\title{
Normalisering van middelengebruik in Nederland
}

Gjalt-Jorn Ygram Peters

This document is the full text of the manuscript "Normalisering van middelengebruik in Nederland", a Dutch manuscript that will be submitted to a Dutch journal.

The most current version of this manuscript is hosted at PsyArXiv at https://psyarxiv.com/7md48 - please check that URL before citing this article.
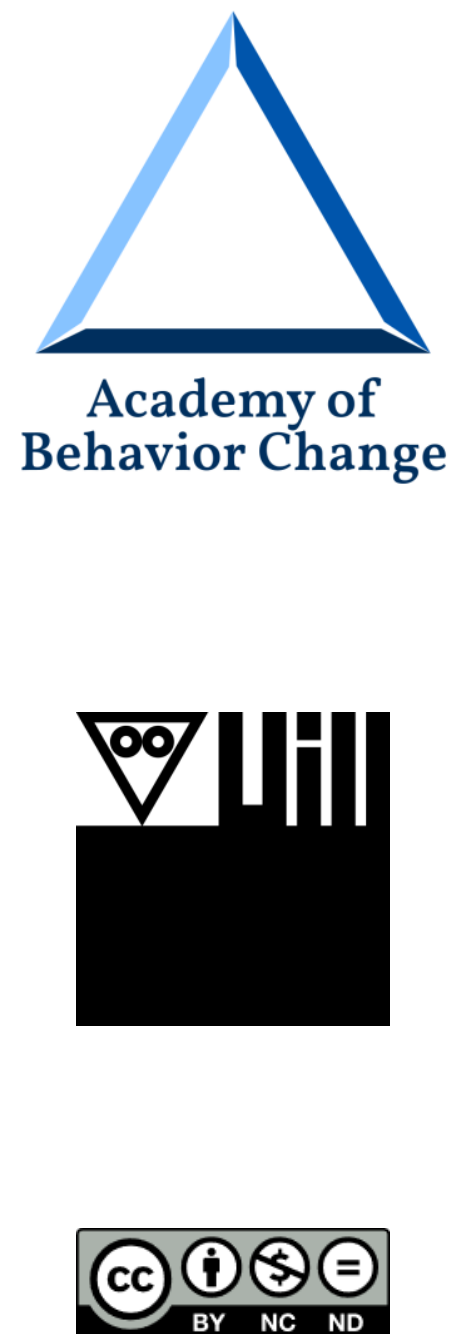


\title{
Normalisering van middelengebruik in Nederland
}

\author{
Gjalt-Jorn Ygram Peters
}

Een van de zorgen die in Nederland speelt met betrekking tot middelengebruik is de angst voor normalisering. Zoals wordt gesteld in het jaarbericht 2016 van de Nationale Drug Monitor is de "kern van de nieuwe beleidsvisie drugspreventie [...] het aanpakken van de normalisering van het drugsgebruik bij met name jongeren en jongvolwassen" (van Laar \& van Ooyen-Houben, 2016, p. 68). In deze bijdrage geef ik een definitie van normalisering, een kort overzicht van normalisering van middelengebruik in Nederland, en sluit ik af met adviezen voor gezondheidsbevordering, beleid, en politiek.

\section{De oorspronkelijke definitie van normalisering van middelengebruik}

Normalisering wordt over het algemeen als positief gezien: het concept beschreef oorspronkelijk pogingen om gestigmatiseerde, gemarginaliseerde groepen zoveel mogelijk deel te laten nemen aan de maatschappij (Parker, Williams, \& Aldridge, 2002). In de jaren negentig werd dit concept toegepast op middelengebruik (Measham, Newcombe, \& Parker, 1994). Zij onderscheiden vijf dimensies van normalisering: toegang en beschikbaarheid van middelengebruik, gangbaarheid van uitproberen van middelen, recent en regelmatig middelengebruik, sociale accommodatie van middelengebruik, en culturele accommodatie van middelengebruik.

De eerste dimensie, toegang en beschikbaarheid van middelen, vormt een noodzakelijke voorwaarde voor normalisering: als middelen niet beschikbaar zijn, kan het gebruik ook niet normaliseren. Deze dimensie betreft niet alleen het bestaan van middelen, maar ook bijvoorbeeld de prijs: duurdere middelen kunnen volgens deze definitie dus niet als genormaliseerd worden beschouwd vanwege de beperkte toegang. De tweede dimensie betreft het uitproberen, en wordt onderscheiden van de derde dimensie, het gebruik (terecht; dit zijn verschillende gedragingen; Peters, 
2008). Indicatoren voor deze twee dimensies zijn bijvoorbeeld 'ooit-prevalentie' en 'laatste-maandprevalentie' (gebruik in het afgelopen jaar is minder eenduidig indicatief voor actief gebruik dan gebruik in de afgelopen maand). Deze kunnen verschillen.

In 2017 had 91\% van de Nederlanders ooit alcohol gedronken, maar 79.5\% had in het afgelopen jaar alcohol gedronken (referentie naar Statline). Dat betekent dat van degenen die ooit alcohol hadden gedronken, $87 \%$ ook 'gebruiker' was. In Nederland zijn geen cijfers over de laatste-maandprevalentie in de algemene bevolking, maar van de 18-jarige MBO- en $\mathrm{HBO}$-studenten had $73.1 \%$ in de afgelopen maand alcohol gebruikt, in een steekproef waar $85.5 \%$ ooit alcohol had gebruikt (Verdurmen, van Dorsselaer, \& Monshouwer, 2016). Bij alcohol lijkt de verhouding tussen 'ooitgebruikers', waaronder 'uitprobeerders', en 'gebruikers' dus ergens tussen de één op twee en de één op een te liggen. In 2017 had 55.7\% van de Nederlanders ooit gerookt (Centraal Bureau voor de Statistiek, 2019), en $23.1 \%$ gaf aan ooit wel eens te roken, terwijl 17.2\% aangaf dagelijks te roken (Rijksinstituut voor Volksgezondheid en Milieu, 2018; bij roken zijn, net als bij alcohol, geen laatstemaand en laatste-jaar prevalenties bekend voor de algemene bevolking). De verhouding tussen ooitgebruikers (waaronder uitprobeerders) en gebruikers ligt hier dus iets lager. Bij cannabis liggen 'ooitprevalentie' en 'laatste-maand-prevalentie' op respectievelijk 20.9\% en $4.1 \%$ (een vijfde), bij XTC op $7.6 \%$ en $1 \%$ (een achtste), en bij cocaine op $4.9 \%$ en $0.8 \%$ (een zesde; Centraal Bureau voor de Statistiek, 2019). Slechts een deel van de mensen die een middel uitprobeert wordt dus gebruiker.

De vierde en vijfde dimensies, sociale en culturele accommodatie van middelengebruik, betreffen opvattingen over het middelengebruik in de populatie. In termen van gedragsverandering betreft dit de determinanten die binnen de Reasoned Action Approach (Fishbein \& Ajzen, 2010) onder de waargenomen norm vallen: denken mensen dat een gedrag veel voorkomt (vooral onder sociale referenten waar ze zich mee identificeren), en denken ze dat hun omgeving het goed- of afkeurt als zij het gedrag zelf uitvoeren? Er kan hier onderscheid worden gemaakt tussen normen met betrekking tot het gedrag zelf (middelengebruik) en normen met betrekking tot bijvoorbeeld middelengebruik 
door anderen. Op maatschappelijk niveau manifesteren dergelijke normen zich, als ze breed worden gedragen tenminste, als sociale normen, en als deze positief zijn tegenover het middelengebruik, dan betekent dat dat gebruikers zich minder schamen voor hun gebruik, en dit eerder zullen bespreken met anderen, zoals 'peers' (levensstijlgenoten), collega's, en familieleden.

In deze laatste twee dimensies ligt de kern van waarom normalisering van oudsher een wenselijke toestand beschrijft. Stigmatisering kan zeer schadelijk zijn (Bos, Kanner, Muris, Janssen, \& Mayer, 2009; Bos, Pryor, Reeder, \& Stutterheim, 2013; Corrigan \& Watson, 2002), maar naast de directe invloed op de slachtoffers, kan het ook de opvattingen van hulpverleners negatief beïnvloeden (van Boekel, Brouwers, van Weeghel, \& Garretsen, 2015), en specifiek met betrekking tot middelengebruik bijvoorbeeld voorkomen dat mensen bij incidenten de eerste hulp faciliteiten benaderen (Peters \& Noijen, 2016). Stigmatisering maakt de risicogroep dus moeilijk bereikbaar, en het is daarom belangrijk om negatieve normen ten opzichte van middelengebruik te voorkomen. Dit is precies waar normalisering voor kan worden ingezet, zodat effectievere preventie mogelijk is en schade door middelengebruik zoveel mogelijk kan worden voorkomen.

\section{'Normalisering' zoals de term nu wordt gebruikt}

Deze oorspronkelijke definitie van normalisering lijkt echter niet de definitie te zijn zoals hij tegenwoordig wordt gehanteerd in Nederland. Zo sprak de Staatssecretaris van Volksgezondheid, Welzijn en Sport in een brief aan de voorzitter van de Tweede Kamer in november 2015 over de in zijn ogen "zeer zorgelijke ontwikkeling van normalisering van het gebruik van drugs tijdens het uitgaan" en zei "[om] deze normalisering tegen te gaan en gezondheidsschade te voorkomen neem ik de volgende maatregelen, die ik in deze brief zal toelichten." (T.K.24077-357, 2016). Hoewel de term 'normalisering' dus veelvuldig wordt gebruikt, is niet duidelijk wat hier nu mee wordt bedoeld. Omdat de definitie van normalisering zoals tegenwoordig gebruikt wel duidelijk afwijkt van de oorspronkelijke definitie is het belangrijk om helder te krijgen wat wordt bedoeld met de nieuwe definitie. 
De eerder genoemde brief benoemt alleen prevalentie van gebruik in een zeer eng gedefinieerde doelgroep: “Onder jongeren en jongvolwassenen die vaak een party of festival bezoeken is het normaal geworden om daar drugs te gebruiken: zo gebruikt meer dan de helft van hen XTC.3”, waarbij voetnoot 3 staat voor: “Frequente uitgaanders: frequente party- en clubbezoekers met een voorkeur voor techno- en hardhouse waarvan meer dan de helft van deze uitgaanders meermaals per maand een party, festival en/of club bezoekt. De gemiddelde leeftijd is circa 15-35 jaar.".

Enerzijds lijkt deze definitie de hand van prevalentie goed aan te sluiten op een van de vijf dimensies van normalisering zoals gedefinieerd door Measham et al. (1994), te weten die van recent en regelmatig middelengebruik. Anderzijds was er in die definitie geen sprake van de extreme inkadering binnen een klein, niet representatief segment van de populatie zoals wel het geval is in de brief van de minister: zelfs binnen de groep uitgaanders van 15-35 jaar zijn er relatief weinig mensen die zowel een voorkeur hebben voor techno- en hardhouse als zeer frequent clubs, festivals of feesten bezoeken. Het gebruik van 'normalisering' hier lijkt dus niet te betekenen dat iets 'normaal' wordt in de betekenis van 'prevalent' (slechts 2.9\% van de bevolking heeft in het laatste jaar XTC gebruikt; van Laar \& van Gestel, 2017). Wat wel opvalt is dat deze definitie van 'normalisering' in beginsel lijkt te veronderstellen dat normalisering onwenselijk zou zijn.

Als normalisering alleen zou worden gedefinieerd als prevalentie is dat niet vanzelfsprekend. XTC is hier een goed voorbeeld van: hoewel het een van de meest gebruikte middelen is levert het bijna geen gezondheidsproblemen op. In 2016 gebruikte bijvoorbeeld naar schatting ongeveer 390000 Nederlanders XTC (2.9\% van de bevolking), en er wordt geschat dat hier ongeveer 5 mensen aan zijn overleden (0.00128\%, oftewel een kans van 1.3 op de 100000 gebruikers; van Laar \& van Gestel, 2017). Om dit in perspectief te plaatsen: alcohol wordt, als een van de meest populaire middelen, elk jaar door ruim 10700000 mensen gebruikt, en een zeer conservatieve schatting is dat hier jaarlijks rond de 1000 mensen aan overlijden (0.00935\%, oftewel een kans van 9.3 op de 1000000 gebruikers; van Laar 
\& van Gestel, 2017). Een alcoholgebruiker heeft dus een ruim zeven keer grotere kans om te sterven door dat middelengebruik dan een XTC-gebruiker door dat middelengebruik; en de schatting van het aantal doden door alcohol bevat bijvoorbeeld nog niet de verkeersdoden, waardoor deze verhouding eigenlijk nog een onderschatting is (STAP rapporteert bijvoorbeeld WHO-cijfers die suggereren dat er 3751 doden waren door alcoholgebruik in 2012; “Feiten en Cijfers,” 2018).

Middelengebruik gaat niet alleen gepaard met acute risico's, maar er kunnen ook beschadigingen optreden op de lange termijn. Onderzoek naar hersenbeschadiging door XTC-gebruik is lastig omdat, gegeven mogelijke schadelijkheid, een experimentele studieopzet niet mogelijk is. Omdat gebruikers vaak meerdere middelen gebruiken, gebruik van uitgaansdrugs vaak gepaard gaat met slecht slapen en eten, en eventuele verschillen met niet-gebruikers bovendien los van het middelengebruik kunnen staan, is het lastig mogelijke gevolgen van XTC-gebruik in kaart te brengen. In Nederland is de NeXT studie opgezet, waar mensen die mogelijk XTC wilden gaan gebruiken zijn geworven (de Win et al., 2005). Dit maakte het mogelijk om bij degenen die ook daadwerkelijk XTC gingen gebruiken onderzoek te doen zonder een aantal van de voorkomende methodologische problemen bij dit soort onderzoek. In deze innovatie studie werd geen evidentie gevonden van schade door matig XTC-gebruik. De Win et al. vergeleken de hersenen van 31 deelnemers voor en na het gebruik van maximaal tien XTC-pillen (Tabel 2; de Win et al., 2007). Van de 41 indicatoren van mogelijke beschadiging vonden ze na correctie voor multipele toetsing slechts één significant verschil, waar er op basis van kans twee te verwachten zijn als er nergens verschil zou zijn (Tabel 2; de Win et al., 2007). Ook andere analyses in deze studie lieten geen effecten zien (Jager et al., 2007). Deze bevindingen zijn consistent met een recente review van studies naar neurologische schade bij recreatief XTC-gebruikers, gedefinieerd als mensen die minder dan 100 pillen in hun leven hadden gebruikt, die geen evidentie vond voor schade in de 19 geïncludeerde studies (Mueller et al., 2016; zie ook Szigeti, Winstock, Erritzoe, \& Maier, 2018). Het merendeel van de studies laat wel effecten zien, maar in steekproeven uit uitzonderlijk zwaar gebruikende populaties (naar schatting de 5-10\% zwaarste gebruikers, die per jaar meer dan zeven keer zoveel gebruikt als een meer representatieve 
groep; Szigeti et al., 2018). Er lijkt dus een dosis-respons relatie te bestaan, maar omdat de meeste studies relatief zware gebruikers onderzochten, is alleen duidelijk dat zwaar gebruik kan leiden tot aantasting van geheugen en concentratievermogen en stemmingsproblemen, terwijl bij matig gebruik die effecten uit lijken te blijven. Wanneer de risico's precies toe beginnen te nemen, en of de effecten herstellen als het gebruik stopt, blijft onbekend (van Laar \& van Gestel, 2019).

Kortom, prevalentie is niet proportioneel met risico en schadelijkheid. Fluctuaties in de prevalentie van middelen zijn dus in zichzelf geen reden tot zorg, en het zou dus onredelijk zijn (en lijkt daarom niet aannemelijk) als prevalenties ten grondslag liggen aan de zorgen over deze nieuwe definitie van 'normalisering', of hier een belangrijk deel van uitmaken (de lage prevalentie van XTC in vergelijking met bijvoorbeeld het veel schadelijkere alcohol is hiermee in lijn). Sterker nog, een daling in de prevalentie van een middel kan tegelijkertijd een stijging in de prevalentie van een ander middel betekenen als gebruikers van middel wisselen. Zulke substitutie vindt plaats als een middel bijvoorbeeld moeilijker verkrijgbaar wordt of duurder wordt (Cole et al., 2008; Goudie, Sumnall, Field, Clayton, \& Cole, 2007; Reiman, 2009; Sumnall, Tyler, Wagstaff, \& Cole, 2004; terwijl kwaliteit maar deels van invloed blijkt, zie Brunt, Niesink, \& van den Brink, 2012).

Gegeven dat prevalentie dus een negatief verband kan vertonen met de gezondheid van individuele gebruikers en gezondheidsrisico's en schade op maatschappelijk niveau moge duidelijk zijn dat prevalentie geen bruikbare indicator is voor risico en schadelijkheid. Dan blijft het echter onduidelijk wat wordt bedoeld met normalisering van middelengebruik zoals hier tegenwoordig vaak aan wordt gerefereerd: als een onwenselijk fenomeen dat een halt toegeroepen dient te worden. De ontwikkeling van het gebruik van een aantal middelen in Nederland kan wellicht helpen dit te begrijpen. Voordat ik specifiek in ga op XTC, zal ik als kader eerst van vijf andere middelen bespreken, of ze zijn genormaliseerd in Nederland, aan de hand van de vijf dimensies in de oorspronkelijke definitie van normalisering.

\section{Normalisering van middelen in Nederland}


Er zijn drie prevalente legale middelen in Nederland: caffeine, alcohol, en tabak.

Koffieconsumptie is wijdverbreid (e.g., Gelder et al., 2007; Kleemola, Jousilahti, Pietinen, Vartiainen, \& Tuomilehto, 2000). Koffie heeft als enige middel duidelijke gezondheidsvoordelen en praktisch geen risico's (Poole et al., 2017), en is dan ook goed verkrijgbaar en toegankelijk, wordt door veel mensen geprobeerd en gebruikt, en is zowel sociaal als cultureel geaccommodeerd.

Alcohol wordt ook veel gebruikt (slechts 3.8\% wordt door de WHO gekwalificeert als ‘lifetime abstainers', en $88.2 \%$ heeft het afgelopen jaar alcohol gedronken; WHO, 2014a), maar is uitzonderlijk schadelijk (WHO, 2014b). Desalniettemin is alcohol goed toegankelijk, wordt het veel uitgeprobeerd en gebruikt, en is het ook sociaal en cultureel geaccommodeerd. Deze accommodatie is wel iets lager dan bij koffie; bij het ontbijt of tijdens het werk wordt alcoholgebruik, anders dan koffiegebruik, niet breed geaccepteerd. Hoewel inmiddels duidelijk is dat alcohol zeer schadelijk is, was dat niet altijd zo duidelijk, en omdat water vroeger vaak niet goed drinkbaar was, werd laag-alcoholisch bier vaak geprefereerd (Vallee, 1998). Dit kan wellicht deels verklaren waarom alcohol is genormaliseerd. $\mathrm{Nu}$ duidelijk is hoe schadelijk alcohol is, worden alcoholrichtlijnen strenger (de WHO adviseert nu om geen alcohol te drinken, of anders maximaal een eenheid per dag): misschien een voorbode van uiteindelijke denormalisering.

Ditzelfde patroon is zichtbaar bij tabak: dit werd oorspronkelijk aangeprezen, onder andere door artsen, als gezondheidsmiddel (Russo, Nastrucci, Alzetta, \& Szalai, 2011). Sigaretten waren destijds breed verkrijgbaar, en ruim de helft van de Nederlandse bevolking rookte. Bij sociale gelegenheden werden gasten zowel van sigaretten als van alcohol voorzien en niemand keek op als er sigaretten aan werden geboden aan jongeren. Tabak was dus ook sociaal en cultureel geaccommodeerd. Nadat de schadelijke effecten breder bekend zijn geworden is over de decennia een keur aan maatregelen getroffen waardoor roken nu weer aan het denormaliseren is (Willemsen, 2017).

Cocaïne is, net als tabak, genormaliseerd geweest. In 1900 is De Nederlandsche Cocaïnefabriek opgericht, en de productie van cocaïne werd pas in de jaren zestig illegaal (Bosman, 2012). Ook aan 
cocaïne werden oorspronkelijk positieve gezondheidseffecten toegeschreven, en het was een populair middel tegen astma en hooikoorts (Boucher, 1991). Aanwezigheid (tot 1903) in een bekende frisdrank die haar naam eraan ontleende en lofzangen in algemeen verkrijgbare boeken (door bijvoorbeeld Sigmund Freud en Mark Twain; Boucher, 1991) impliceren dat cocaïne niet alleen breed verkrijgbaar was, maar ook sociaal en cultureel was geaccommodeerd. Toen echter de risico's duidelijk werden is cocaïne illegaal geworden, waarna gebruik snel afnam. In 2016 had $4.9 \%$ van de bevolking ooit cocaïne gebruikt, waarvan $1.7 \%$ in het afgelopen jaar en $0.8 \%$ in de afgelopen maand (van Laar \& van Gestel, 2017).

Als laatste voorbeeld bespreken we cannabis. Het gedoogbeleid maakt cannabis tot een speciaal geval. Cannabis is breed verkrijgbaar, maar wordt weinig gebruikt. Zoals eerder aangegeven heeft $4.1 \%$ van de Nederlandse bevolking in de laatste maand cannabis gebruikt. Dit ongeveer gelijk aan het Europese gemiddelde, dat op 4.2\% ligt (Thanki et al., 2012) en de helft van de prevalentie in Amerika, waar cannabisgebruik illegaal is (8.3\%; National Academies of Sciences, Engineering, and Medicine, 2017). Naast deze lage prevalentie is cannabisgebruik minder sociaal en cultureel geaccommodeerd dan alcohol en koffie. Tabak is op weg om evenmin sociaal geaccommodeerd te worden. Van cannabis is dus al lastiger te stellen of het is genormaliseerd volgens de oorspronkelijke definitie. Dat er niet over wordt gerept in de recente beleidsstukken over normalisering impliceert dat cannabis ook volgens de tegenwoordig gebruikte definitie van normalisering niet is genormaliseerd.

\section{Normalisering van uitgaansdrugs in Nederland}

Deze korte bespreking van middelen doet vermoeden dat als wenselijke (gezondheids)effecten aan een middel worden toegeschreven, dit normalisering (in de oorspronkelijke definitie) in de hand werkt. Omgekeerd kan een middel weer denormaliseren als blijkt dat het negatieve gezondheidseffecten heeft, bijvoorbeeld als gevolg van wetgeving, beleid, en gezondheidsbevorderingsinterventies. Aan deze mogelijke voorwaarde voor normalisering wordt bij uitgaansdrugs niet voldaan. Als voorbeeld bespreken we XTC. Hoewel toepassingen bij behandeling 
van psychopathologie steeds meer worden onderzocht (Thal \& Lommen, 2018) worden aan XTC vooralsnog geen algemene positieve gezondheidseffecten toegeschreven. Verder is de productie en verkoop van XTC, net als van andere uitgaansdrugs, illegaal. Dit betekent dat uitgaansdrugs niet kunnen normaliseren in de eerste dimensie van normalisering totdat ze worden gelegaliseerd. De percentages van de bevolking die uitgaansdrugs uitproberen en gebruiken zijn, zoals eerder genoemd, een fractie van diezelfde percentages van middelen als koffie, alcohol en tabak.

Wat als we alleen kijken in de context van het uitgaansleven? Verkrijgbaarheid kan enerzijds als relatief laag worden bezien: omdat verkoop illegaal is, vereist verkrijgbaarheid toegang tot een dealer of het dark web. Anderzijds kan toegang tot dealers voor frequente uitgaanders wellicht dermate veelvoorkomend zijn dat dit in de praktijk amper een barrière vormt. Omdat 'uitgaansdrugs' letterlijk per definitie middelen zijn die vooral of alleen in het uitgaansleven worden gebruikt, worden deze middelen noodzakelijkerwijs meer uitgeprobeerd en gebruikt in het uitgaansleven dan in de algemene populatie. Hier zijn echter geen gegevens over bekend. Er zijn twee intitiatieven die hier informatie over kunnen geven, maar beide lijden aan zelfselectie van deelnemers van onbekende omvang en op ombekende verstorende variabelen. Ten eerste wordt elk jaar de Party Panel studie uitgevoerd (Gjalt-Jorn Ygram Peters \& Noijen, 2019), waar voor steeds verschillende uitgaanslevengerelateerde risicogedragingen de determinanten in kaart worden gebracht. De ronde in 2015 ging over hooggedoseerde XTC (Gjalt-Jorn Ygram Peters \& Noijen, 2015); die in 2016 over het bezoeken van de eerste hulp in het uitgaansleven (Gjalt-Jorn Ygram Peters \& Noijen, 2016); die in 2017 over gehoorbescherming (Gjalt-Jorn Ygram Peters \& Noijen, 2017); en die in 2018 over seksueel grensoverschrijdend risicogedrag (Gjalt-Jorn Ygram Peters \& Noijen, 2018). Vooral bij rondes over aan middelengebruik gerelateerde onderwerpen lijkt zelfselectie plausibel. Middelengebruik is gemeten in 2015, 2016, en 2018. In 2015 werd 79\% van de deelnemers als XTC-gebruiker geclassificeerd; in 2016, 60\%; en in 2018, 50\%. 
Ten tweede heeft het Trimbos Instituut twee keer een ‘Groot Uitgaansonderzoek' gedaan (Goossens, Frijns, Van Hasselt, \& van Laar, 2013; Monshouwer, van der Pol, Drost, \& van Laar, 2016), die zich expliciet richt op middelengebruik in het uitgaansleven. Die saillantie van middelengebruik maakt het waarschijnlijk dat zelfselectie van de steekproef ertoe leidt dat prevalentieschattingen (forse) overschattingen zijn. In de steekproef uit 2013 had ongeveer 32.5\% ooit cocaïne gebruikt (uitproberen), en $12.4 \%$ in de afgelopen maand; $55.1 \%$ had ooit ecstasy gebruikt, en $21.6 \%$ in de afgelopen maand; en 13.8\% had ooit GHB gebruikt, en 3\% in de afgelopen maand. Ter vergelijking: in deze steekproef had $99.2 \%$ ooit alcohol gebruikt, $96 \%$ in de afgelopen maand; en $80.1 \%$ had ooit tabak gebruikt, 58\% in de afgelopen maand (Monshouwer et al., 2016).

Omdat de Party Panel en Grote Uitgaansleven studies lijden aan zelfselectie en de gevonden prevalenties dus overschattingen zijn, kan het zinvol zijn te kijken naar gebruikscijfers in de algemene populatie in de leeftijdsgroep die het sterkst vertegenwoordigd is in het uitgaansleven. Het Centraal Bureau voor de Statistiek heeft prevalentiecijfers per leeftijdsgroep, en in de subpopulatie van jonge volwassenen van 20-30 ligt het laatste-jaar gebruik op 10.5\%, en het laatste-maand gebruik op 3.2\% (Centraal Bureau voor de Statistiek, 2019). Ook op deze dimensies lijkt XTC verre van genormaliseerd, en XTC is de meest gebruikte uitgaansdrug (van Laar \& van Gestel, 2019).

De inschattingen van prevalentie lijken verder niet gestegen in de afgelopen decennia. In het Antenne onderzoek, dat met een combinatie van kwalitatieve en kwantitatieve methoden een vinger aan de pols van het Amsterdame uitgaansleven houdt, werd in 1995 een laatste-maand prevalentie voor XTC-gebruik van 3\% gevonden onder Amsterdamse studenten, en dit percentage lag op 33\% onder de deelnemers uit het club-circuit (Korf, Nabben, \& Schreuders, 1995). Van de Wijngaart, Braam, de Bruin, Fris, Maalsté en Verbraeck rapporteerden in 1999 data die waren verzameld onder feestgangers waar deze prevalenties aanmerkelijk hoger lagen: $81 \%$ had ooit XTC gebruikt, $68 \%$ in de afgelopen drie maanden, en $64 \%$ in de afgelopen nacht; $40 \%$ had ooit cocaine gebruikt, $24 \%$ in de afgelopen drie maanden, en $7 \%$ in de afgelopen nacht; $91 \%$ had ooit alcohol gebruikt, $82 \%$ in de 
afgelopen drie maanden, en $34 \%$ in de afgelopen nacht; en $78 \%$ had ooit tabak gebruikt, $75 \%$ in de afgelopen drie maanden, en 75\% in de afgelopen nacht (van de Wijngaart et al., 1999). In 2000 en 2001 deden 844 bezoekers van zeven dance feesten mee met een studie naar XTC-gerelateerde verwachtingen, en van deze deelnemers gaf $65 \%$ aan XTC te gebruiken (Engels \& ter Bogt, 2004). In 2005 werd in een grootschalige survey naar opvattingen over XTC-gebruik onder bijna zeven duizend uitgaanders 59\% gecategoriseerd als gebruiker (Gjalt-Jorn Ygram Peters, 2008).

Tot slot lijken uitgaansdrugs ook niet sociaal en cultureel geaccommodeerd: zoals de minister al benoemde is gebruik grotendeels beperkt tot specifieke contexten en doelgroepen, en de definitie van normalisering maakt het al bijna onmogelijk over normalisering te spreken als eenmaal binnen subgroepen wordt gekeken. Dit zou de term ook triviaal maken: noodzakelijkerwijs geldt voor elk gedrag dat plaatsvindt dat er een subpopulatie te definieren valt waar de prevalentie van dat gedrag hoog ligt. Dat er een subpopulatie bestaat waar een gedrag veel voorkomt is dus niet informatief.

\section{Normalisering en preventie}

Er lijkt de afgelopen decennia dus geen toename te hebben plaatsgevonden in het gebruik van uitgaansdrugs in de Nederlandse maatschappij, noch lijkt er de afgelopen jaren sprake van een stijging. Dat XTC zich ontwikkeld tot eenzelfde genormaliseerde status als koffie of alcohol is op basis van de ontwikkelingen in de afgelopen decennia en jaren, en gegeven de definitie van normalisering, dus niet waarschijnlijk. Uitgaansdrugs lijken verder ook niet te voldoen aan de definitie van normalisering. Als er wordt gesproken over normalisering van XTC-gebruik, wat wordt er dan precies bedoeld? Een aantal betekenissen kunnen op basis van de evidentie die ik heb besproken worden uitgesloten: er wordt niet bedoeld dat XTC-gebruik prevalent is, dat het gebruik toeneemt, of dat XTC-gebruik de maatschappij (of haar gebruikers) veel schade toebrengt. Geen van die zaken zijn het geval. Het is mogelijk dat niet wordt gerefereerd aan patronen met betrekking tot middelengebruik of risico's voor de volksgezondheid, maar dat de angst voor 'normalisering' het idee uitdrukt dat het gebruik van uitgaansdrugs intrinsiek slecht is, dus los van of die uitgaansdrugs 
schadelijk zijn. Een dergelijk standpunt is echter niet te rijmen met een beleid dat is gebaseerd op evidentie en redelijkheid, en kan daardoor schadelijk zijn voor de volksgezondheid. Het lijkt er dus op dat er simpelweg geen sprake is van normalisering, en dat hiervoor bovendien niet gevreesd hoeft te worden. Verder wijst de evidentie er op dat de meeste gebruikers van uitgaansdrugs zonder interventie op een gegeven moment stoppen (Peters, Kok, \& Schaalma, 2008; Ter Bogt, Engels, Hibbel, van Wel, \& Verhagen, 2002): dit verklaart dat de prevalentie in hogere leeftijdsgroepen weer zakt, ondanks dat uitgaansdrugs al sinds de jaren negentig prevalent zijn in het uitgaansleven.

Wat betekenen deze patronen voor drugspreventie in Nederland? Ten eerste is het belangrijk om te beseffen dat er geen sprake lijkt van urgentie om te interveniëren: de situatie met betrekking tot prevalentie van uitgaansdrugs is al decennia relatief stabiel. Het gegeven dat uitgaansdrugs slechts een fractie van de slachtoffers maken van alcohol suggereert dat de harm reduction insteek die de Nederlandse drugspreventie altijd heeft gekenmerkt een verstandige insteek is. Er zijn echter wel slachtoffers, en deze zouden leidend moeten zijn in het beleid. Het lijkt daarom aangewezen om een dubbel spoor te hanteren. Enerzijds moet de voorlichting voor de gebruikers van uitgaansdrugs die hier geen schade van ondervinden worden voortgezet. Het blijft belangrijk om trends te monitoren en preventieboodschappen te kunnen afstemmen op de doelgroep. Anderzijds is het belangrijk om vooral degenen die in de problemen komen met middelengebruik in kaart te brengen en te ondersteunen. Er is meer onderzoek nodig naar de patronen met betrekking tot combigebruik van uitgaansdrugs en determinanten van die patronen, zodat er interventies ontwikkeld kunnen worden op basis van theorie en evidentie (Bartholomew Eldredge et al., 2016; Kok et al., 2016; Peters, 2014).

Het is tot slot belangrijk dat middelengebruik zoveel mogelijk bespreekbaar wordt gemaakt waar het dat al niet is. Door er zorg voor te dragen dat er niet naar het gebruik van XTC en andere uitgaandrugs wordt verwezen als moreel verwerpelijk kan toegang tot de gebruikersgroep worden bewaakt. Zo wordt voorkomen dat er drempels worden opgeworpen voor gebruikers met een hulpvraag. Dit voorkomt bovendien stigmatisering en maakt het optimaliseren van preventie- 
activiteiten mogelijk. Het is belangrijk om te onthouden dat mensen drugs deels als uitwisselbaar beschouwen; afname van de prevalentie van het ene middel zal dus vaak leiden tot een toename van de prevalentie van een ander middel (Cole et al., 2008; Goudie et al., 2007; Sumnall et al., 2004). Als bijvoorbeeld de prevalentie van XTC-gebruik zou afnemen in Nederland, zullen die gebruikers deels overstappen op middelen zoals cocaïne, 4-fluoroamfetamine, ketamine, of alcohol. Gegeven dat bijvoorbeeld alcohol en cocaïne veel schadelijker zijn dan XTC (Nutt, King, \& Phillips, 2010; van Amsterdam, Opperhuizen, Koeter, \& van den Brink, 2010; van Amsterdam \& van den Brink, 2010) is het belangrijk niet zonder meer te streven naar het verlagen van de prevalentie van XTC of andere middelen. Dit zou makkelijk kunnen leiden tot onbedoelde iatrogene effecten als alcoholgebruik hierdoor zou toenemen.

Voor nu lijkt er dus de meeste gezondheidswinst te behalen door de aandacht te richten op degenen die uitgaandrugs frequent gebruiken, intensief gebruiken, of veelvuldig combineren. Hoewel er in deze groep zeker nog ruimte is voor verbetering, is angst voor 'normalisering' niet gerechtvaardigd. Uitgaandrugs zijn niet meer weg te denken, maar er is geen evidentie dat dit bijzonder schadelijk is voor de samenleving of dat gebruik toe lijkt te nemen.

\section{Referenties}

Bartholomew Eldredge, L. K., Markham, C. M., Ruiter, R. A. C., Fernàndez, M. E., Kok, G., \& Parcel, G. S. (2016). Planning health promotion programs: An Intervention Mapping approach. San Francisco: Jossey-Bass.

Bos, A. E. R., Kanner, D., Muris, P., Janssen, B., \& Mayer, B. (2009). Mental illness stigma and disclosure: Consequences of coming out of the closet. Issues in Mental Health Nursing, 30(8), 509-513.

Bos, A. E. R., Pryor, J. B., Reeder, G. D., \& Stutterheim, S. E. (2013). Stigma: advances in theory and research. Basic and Applied Social Psychology, 35(1), 1-9. 
Bosman, H. (2012). The History of the Nederlandsche Cocaïne Fabriek and its Successors (Vol. 1). Foot \& Playsted Pty. Ltd., Launceston, Tasmania.

Boucher, D. H. (1991). Cocaine and the coca plant. BioScience, 41(2), 72-76.

Brunt, T. M., Niesink, R. J. M., \& van den Brink, W. (2012). Impact of a transient instability of the ecstasy market on health concerns and drug use patterns in The Netherlands. International Journal of Drug Policy, 23(2), 134-140. https://doi.org/10.1016/j.drugpo.2011.05.016

Centraal Bureau voor de Statistiek. (2019). Leefstijl en (preventief) gezondheidsonderzoek; persoonskenmerken. Retrieved from https://opendata.cbs.nl/statline/\#/CBS/nl/dataset/83021NED/table?dl=13DDD

Cole, J. C., Goudie, A. J., Field, M., Loverseed, A.-C., Charlton, S., \& Sumnall, H. R. (2008). The effects of perceived quality on the behavioural economics of alcohol, amphetamine, cannabis, cocaine, and ecstasy purchases. Drug and Alcohol Dependence, 94(1), 183-190. https://doi.org/10.1016/j.drugalcdep.2007.11.014

Corrigan, P. W., \& Watson, A. C. (2002). Understanding the impact of stigma on people with mental illness. World Psychiatry, 1(1), 16-20.

de Win, M. M. L., Jager, G., Vervaeke, H. K. E., Schilt, T., Reneman, L., Booij, J., ... van den Brink, W. (2005). The Netherlands XTC Toxicity (NeXT) study: Objectives and methods of a study investigating causality, course, and clinical relevance. International Journal of Methods in Psychiatric Research, 14(4), 167-185.

de Win, M. M. L., Reneman, L., Jager, G., Vlieger, E. J. P., Olabarriaga, S. D., Lavini, C., ... van den Brink, W. (2007). A Prospective Cohort Study on Sustained Effects of Low-Dose Ecstasy Use on the Brain in New Ecstasy Users. Neuropsychopharmacology, 32(2), 458-470.

Engels, R. C., \& ter Bogt, T. (2004). Outcome expectancies and ecstasy use in visitors of rave parties in the Netherlands. European Addiction Research, 10(4), 156-162.

Feiten en Cijfers. (2018). Retrieved August 3, 2018, from http://www.stap.nl/nl/home/feiten-encijfers.html 
Fishbein, M., \& Ajzen, I. (2010). Predicting and Changing Behavior: The Reasoned Action Approach. New York: Taylor \& Francis Group.

Gelder, B. M. van, Buijsse, B., Tijhuis, M., Kalmijn, S., Giampaoli, S., Nissinen, A., \& Kromhout, D. (2007). Coffee consumption is inversely associated with cognitive decline in elderly European men: the FINE Study. European Journal of Clinical Nutrition, 61(2), 226-232. https://doi.org/10.1038/sj.ejcn.1602495

Goossens, F. X., Frijns, T., Van Hasselt, N. E., \& van Laar, M. W. (2013). Het Grote Uitgaansonderzoek 2013. Utrecht: Trimbos Instituut.

Goudie, A. J., Sumnall, H. R., Field, M., Clayton, H., \& Cole, J. C. (2007). The effects of price and perceived quality on the behavioural economics of alcohol, amphetamine, cannabis, cocaine, and ecstasy purchases. Drug and Alcohol Dependence, 89(2-3), 107-115.

Jager, G., de Win, M. M., Vervaeke, H. K., Schilt, T., Kahn, R. S., van den Brink, W., ... Ramsey, N. F. (2007). Incidental use of ecstasy: No evidence for harmful effects on cognitive brain function in a prospective fMRI study. Psychopharmacology, 193(3), 403-414.

Kleemola, P., Jousilahti, P., Pietinen, P., Vartiainen, E., \& Tuomilehto, J. (2000). Coffee Consumption and the Risk of Coronary Heart Disease and Death. Archives of Internal Medicine, 160(22), 3393-3400. https://doi.org/10.1001/archinte.160.22.3393

Kok, G., Gottlieb, N. H., Peters, G.-J. Y., Mullen, P. D., Parcel, G. S., Ruiter, R. A. C., ... Bartholomew, L. K. (2016). A taxonomy of behavior change methods: an Intervention Mapping approach. Health Psychology Review, 10(3), 297-312. https://doi.org/10.1080/17437199.2015.1077155

Korf, D. J., Nabben, T., \& Schreuders, M. (1995). Antenne 1995: trends in alcohol, tabak en drugs bij jonge Amsterdammers [Antenna 1995: Alcohol, tobacco and drug trends among Amsterdam adolescents and young adults]. Amsterdam: Jellinek.

Measham, F., Newcombe, R., \& Parker, H. (1994). The normalization of recreational drug use amongst young people in North-West England, 45(2), 287-312. 
Monshouwer, K., van der Pol, P., Drost, Y., \& van Laar, M. W. (2016). Het Grote Uitgaansonderzoek 2016. Utrecht: Trimbos Instituut.

Mueller, F., Lenz, C., Steiner, M., Dolder, P. C., Walter, M., Lang, U. E., ... Borgwardt, S. (2016). Neuroimaging in moderate MDMA use: A systematic review. Neuroscience \& Biobehavioral Reviews, 62, 21-34. https://doi.org/10.1016/j.neubiorev.2015.12.010

National Academies of Sciences, Engineering, and Medicine. (2017). Cannabis: Prevalence of Use, Regulation, and Current Policy Landscape. Washington, DC: National Academies Press. Retrieved from https://www.ncbi.nlm.nih.gov/books/NBK425763/

Nutt, D. J., King, L. a, \& Phillips, L. D. (2010). Drug harms in the UK: a multicriteria decision analysis. The Lancet, 376. https://doi.org/10.1016/S0140-6736(10)61462-6

Parker, H., Williams, L., \& Aldridge, J. (2002). The Normalization of “Sensible” Recreational Drug Use: Further Evidence from the North West England Longitudinal Study, 36(4), 941-964.

Peters, G.-J. Y. (2008). Determinants of ecstasy use and harm reduction practices: informing evidence-based intervention development. Morrisville, NC: Lulu.com.

Peters, G.-J. Y. (2014). A practical guide to effective behavior change: How to identify what to change in the first place. European Health Psychologist, 16(5), 142-155. https://doi.org/10.31234/osf.io/hy7mj

Peters, G.-J. Y., Kok, G., \& Schaalma, H. P. (2008). Careers in ecstasy use: do ecstasy users cease of their own accord? Implications for intervention development. BMC Public Health, 8(1), 376.

Peters, G.-J. Y., \& Noijen, J. (2015). Party Panel 15.1. Celebrate Safe.

Peters, G.-J. Y., \& Noijen, J. (2016). Party Panel 16.1. Celebrate Safe.

Peters, G.-J. Y., \& Noijen, J. (2017). Party Panel 17.1. Celebrate Safe.

Peters, G.-J. Y., \& Noijen, J. (2018). Party Panel 18.1. Celebrate Safe.

Peters, G.-J. Y., \& Noijen, J. (2019). Party Panel: the architecture of a semi-panel study to flexibly map determinants of nightlife risk behaviors and inform prevention efforts. PsyArXiv. https://doi.org/10.31234/osf.io/akpmx 
Poole, R., Kennedy, O. J., Roderick, P., Fallowfield, J. A., Hayes, P. C., \& Parkes, J. (2017). Coffee consumption and health: umbrella review of meta-analyses of multiple health outcomes. BMJ, 359, j5024. https://doi.org/10.1136/bmj.j5024

Reiman, A. (2009). Cannabis as a substitute for alcohol and other drugs. Harm Reduction Journal, 6(1), 35. https://doi.org/10.1186/1477-7517-6-35

Rijksinstituut voor Volksgezondheid en Milieu. (2018). Roken bij personen van 18 jaar en ouder in 2017. Rijksinstituut voor Volksgezondheid en Milieu. Retrieved from https://www.rivm.nl/documenten/cijfers-over-roken-onder-volwassenen-in-2017

Russo, P., Nastrucci, C., Alzetta, G., \& Szalai, C. (2011). Tobacco Habit: Historical, Cultural, Neurobiological, and Genetic Features of People's Relationship with an Addictive Drug. Perspectives in Biology and Medicine, 54(4), 557-577. https://doi.org/10.1353/pbm.2011.0047

Sumnall, H. R., Tyler, E., Wagstaff, G. F., \& Cole, J. C. (2004). A behavioural economic analysis of alcohol, amphetamine, cocaine and ecstasy purchases by polysubstance misusers. Drug and Alcohol Dependence, 76(1), 93-99.

Szigeti, B., Winstock, A. R., Erritzoe, D., \& Maier, L. J. (2018). Are ecstasy induced serotonergic alterations overestimated for the majority of users? Journal of Psychopharmacology, 32(7), 741748. https://doi.org/10.1177/0269881118767646

Ter Bogt, T., Engels, R., Hibbel, B., van Wel, F., \& Verhagen, S. (2002). “Dancestasy": Dance and MDMA Use in Dutch Youth Culture. Contemporary Drug Problems, 29(1), 157-181. https://doi.org/10.1177/009145090202900107

Thal, S. B., \& Lommen, M. J. J. (2018). Current Perspective on MDMA-Assisted Psychotherapy for Posttraumatic Stress Disorder. Journal of Contemporary Psychotherapy, 48(2), 99-108. https://doi.org/10.1007/s10879-017-9379-2

Thanki, D., Matias, J., Griffiths, P., Noor, A., Olszewski, D., Simon, R., \& Vicente, J. (2012). Prevalence of daily cannabis use in the European Union and Norway. Luxembourg: Publications Office of the European Union. Retrieved from https://doi.org/10.2810/73754 
T.K.24077-357, Tweede Kamer der Staten-Generaal vergaderjaar 2015-2016 publicatienummer 24077 nr.357. (2016). Drugbeleid; Brief regering; Beleidsvisie drugspreventie. Tweede Kamer der StatenGeneraal: Den Haag.

Vallee, B. L. (1998). Alcohol in the Western World. Scientific American, 278(6), 80-85.

van Amsterdam, J., Opperhuizen, A., Koeter, M., \& van den Brink, W. (2010). Ranking the harm of alcohol, tobacco and illicit drugs for the individual and the population. European Addiction Research, 16(4), 202-7. https://doi.org/10.1159/000317249

van Amsterdam, J., \& van den Brink, W. (2010). Ranking of drugs: a more balanced risk-assessment. The Lancet, 376(9752), 1524-1525. https://doi.org/10.1016/S0140-6736(10)62000-4

van Boekel, L. C., Brouwers, E. P. M., van Weeghel, J., \& Garretsen, H. F. L. (2015). Stigmatisering van patiënten met een verslaving en de gevolgen voor de hulpverlening: een systematisch literatuuronderzoek. Tijdschrift Voor Psychiatrie, 57(7), 489-497.

van de Wijngaart, G. F., Braam, R., de Bruin, D., Fris, M., Maalste, N. J. M., \& Verbraeck, H. T. (1999). Ecstasy use at large-scale dance events in the Netherlands, 29(3), 679-702.

van Laar, M. W., \& van Gestel, B. (2017). Nationale Drug Monitor - Jaarbericht 2017. Trimbos Instituut. van Laar, M. W., \& van Gestel, B. (2019). Nationale Drug Monitor - Jaarbericht 2018. Trimbos Instituut. van Laar, M. W., \& van Ooyen-Houben, M. M. J. (2016). Nationale Drug Monitor - Jaarbericht 2016. Trimbos Instituut.

Verdurmen, J. E. E., van Dorsselaer, S. A. F. M., \& Monshouwer, K. (2016). Middelengebruik onder studenten van 16-18 jaar op het MBO en HBO 2015. Utrecht: Trimbos-instituut.

WHO. (2014a). Alcohol use country profile: Netherlands. WHO.

WHO. (2014b). Global status report on alcohol and health 2014. Luxembourg (Luxembourg): World Health Organization.

Willemsen, M. C. (2017). Het Nederlandse tabaksontmoedigingsbeleid. Nederlands Tijdschrift voor Geneeskunde, 161, D949. 